\title{
Aflotoxin: A Higher Threat of Health Hazards for the Bivoltine Silkworms in Temperate Zones - A Review
}

\author{
Shivkumar $^{1^{*}}$, M.A. Ravindra ${ }^{1}$ and M.N. Ramya ${ }^{2}$ \\ ${ }^{1}$ Central Sericultural Research and Training Institute, Central Silk Board, \\ Pampore, Jammu and Kashmir-192121-India \\ ${ }^{2}$ Department of Studies in Sericulture Science, Manasagangothri, University of Mysore, \\ Mysore-570006, Karnataka, India \\ *Corresponding author
}

\begin{tabular}{|l|}
\hline Ke y w o r d s \\
Aflatoxin, \\
Aspergelous fungal \\
disease, Temperate \\
region, Bivoltine, \\
Bombyx mori
\end{tabular}

A B S T R A C T

The main aim of this review study was to know the effects by aflatoxin of mycotoxin fungal diseases for the health hazards of silkworm Bombyx mori and series of events that led to the discovery of aflatoxin as a potent carcinogen. Aflatoxins $B_{1}, B_{2}, G_{1} \& G_{2}$ may be referred as the toxic and produced by the Aspergillus fungal diseases, among all the Aflatoxins, $B_{1}$ and $G_{1}$ are highly toxic to the silkworm, which is carcinogenic in nature and can be occurred immediately higher incidence in bivoltine silkworms than in multivoltine and cross breed. The outbreak of aflatoxin was maximum in early instar larvae compare to later instar larvae \& in the area of high humidity \& temperature during rainy, winter seasons \& also in the unhygienic condition of silkworm rearing rooms and mulberry gardens; etc. The symptoms of toxicity are larvae stop feeding, become lethargic, show body tension, lustrousness, chronic diseases, reproductive interference, immune suppression, finally die soon due to aflatoxin produced by the fungus in the host and will impact on the economic loss of crop productivity of the silkworm Bombyx mori. Hence, a review was framed to prevent the aflatoxin producing fungal attack as a precautionary high alert for the sericulturists of temperate region and may overcome by maintaining optimum temp, RH \& hygienic condition in silkworm rearing climate, minimizes utilization of chemical fertilizers \& insecticides in mulberry garden, developing silkworm breeds or races tolerant to aspergillosis could be a worthwhile attempt by silkworm breeders. Apart, utilization of advanced biotechnological and nano-technological tools for proper control and eradication of aflatoxin contamination and proper care should be taken for persistence and crossing of aflatoxins from other insects to/from mulberry garden \& rearing room in the temperate bivoltine producing zones of the country and abroad.

\section{Introduction}

The insect Bombyx mori gained important not only in sericulture economy stabilization but also in its biological importance. Hence, this insect is considering as one of the model organism for its genetics and molecular, physiological, behavioral, morphological features, etc. The China is the dominated country in the world raw silk production, 
which was discovered and introduced the silkworm/sericulture to the world-wide and the rearing of silkworms have been cultivating for over 5000 years in China for purpose of silk production (Nagaraju and Goldsmith, 2002). Moreover, even though presently China $(146,000$ MT), India (28,708 MT) and Uzbekistan (1,100 MT) are the three countries have occupied first, second and third positions respectively in the raw silk production. Totally, 21 traits play an important role in qualitative and quantitative of silk yield is influenced by healthy developmental stages of silkworm Bombyx mori (Chatterjee et al., 1993). Hence, nourishment of silkworm during its developmental stages required because life traits, which are the effect on qualitative aspects of silk productivity (Ohi et al., 1970). The qualitative and quantitative aspects of silk effects productivity by several silkworm diseases among them the fungal diseases are very dangerous to silkworm. This is a prime focusable disease caused by numerous Aspergillus species of fungi. It has been reported by Nomura, (1897) that, since the latest part of the $19^{\text {th }}$ century, the Aspergillus species have been known to pathogenic to silkworms. Generally, in Japan, it is called as "Kojickabi" (Ayuzawa et al., 1972) and also called as brown muscardine. It has been accepted fact that, more than 10 species of Aspergillus pathogenic to the silkworms are A. flavus, A.tamari, A.oryzac, A.niger, A.ochraceus, A.sojae, A.fmigatus, A.nidulans, A.flavipes, A.clavatus, A.terreus, A.melleus, A.elegans, A.parasiticus, etc from India, Indonesia, Thailand and Srilanka (Govindan and Devaiah, 1995).

Apart, more interesting to know that, the Aspergillus species produce a kind toxic substance called as "Aflatoxin", the aflatoxins can be defined as difuranocyclopentanocumarines/ difuranolidocumarines. It has a dihydrofuran or a tetrahydrofuran ring. In general phenomenon, it is most prioritized vital effects especially on postharvest decays of fruits, vegetables and in particularly seed and feed deterioration by fungi, which produces mycotoxicosis. A report by Agrios, (1978) and Moss, (1989) and Talebi et al., (2011) suggested that the most of the animals, dairy, poultry, livestock, and humans are causes diseases by consumption of feeds and foods invaded by fungi that produce toxic substances called mycotoxins.

However, few interesting investigations showed that aflatoxins are serious health hazard to human beings as well as animals through contamination of food (Diener et al., 1987, Lubulwa and Davis, 1994, Cardwell and Miller, 1996) are correlated between insect damage and aflatoxin contamination (Bowen and Mack, 1991, Lynch and Wilson, 1991, Lynch et al., 1991 and Gorman and Kang, 1991) and influenced of insect infestation on aflatoxin contamination of stored maize was studied in four agroecological zones in Benin (Hell et al., 2000). Apart, observations were made by Sinha and Sinha, (1991 \&1992) together revealed that the incidence of fungi of the A. flavus group and aflatoxin contamination was high by insect-damaged in maize than in insect free samples in India. Furthermore, few investigations also suggested that insects could act as a vector by transporting spores of fungal on their bodies, then contaminating grains as they moved about (Lynch and Wilson, 1991). According to Lussenhop and Wilcklow, (1991), finding revealed that few vital insects are acting like victors of $A$. flavus are carporphilus lugubris Murry and C.freemani Dobson on maize. Apart, Sauer and Burroughs, (1980) and Mills, (1983) reported that the environmental effect like in increased relative humidity $(\mathrm{RH})$ also provides support to A. flavus growth through which seed germination almost reduced in the corn plant. Moreover, the accumulation of aflatoxin, the relative humidity, and temperature, as well as agroecological zones, 
are playing a very vital role, in addition to that for the development of aflatoxin is influenced by insects related fungi, maize varieties, polished \& brown rice (Barry et al., 1992 and Mousa et al., 2013).

However, in sericulture industry mulberry, which is a primary source of food plant for silkworms and these plants are generally attacked by numerous fungal diseases like leaf spot, leaf rust, powdery mildew, root rot, rootknot, nematode, and intern ultimately causes of silkworm fungal diseases by consuming fungal infested mulberry leaves. The aflatoxin viz., $\mathrm{B}_{1}, \mathrm{~B}_{2}, \mathrm{G}_{1} \& \mathrm{G}_{2}$ are may be referred as the Aspergillus agent or toxic substances produced by silkworm Aspergillus fungal diseases $\&$ among all above said aflatoxins $\mathrm{B}_{1}$ $\& \mathrm{G}_{1}$ are highly toxic \& carcinogenic to the Bombyx mori. Through the review of literatures, it has been digested and cleared that, the food, variability in environmental condition, stagnant aeration, unhygienic condition in the silkworm rearing rooms and mulberry garden, excess utilization of chemical fertilizers \& insecticides, environmental factors and while transporting agents like insects and other sources are key factors to cause the fungal diseases. Hence, keeping the above concepts in our mind, it has boosted our interest to glance in this direction to present a review on the aflatoxin, which are toxic substances produced by Aspergillus fungal disease a threat of health hazards for the bivoltine silkworm Bombyx mori.

\section{Discovery of aflatoxin and its process of distribution in different animals/livestock/others}

The aflatoxin was primarily discovered 50 years ago in England as the causative agent of the "Turkey X" disease in 1960. Hence, the outbreak of the aflatoxicosis popularly known as the Turkey $\mathrm{X}$ disease. Because of this disease, there was the death of a large population of livestock (Blount, 1961 and Vander Zijden et al., 1962) and this is the main reason, which helped for the discovery of aflatoxin in groundnut meal contaminated by A. flavus (Hesseltine, 1979). Further, this is also investigated in maize (Shotwell, 1977, Chakrabarty, 1981) and cottonseed meal (Lillehoj, 1979 and Sharma et al., 1994). Apart, few other important findings like Busby and Wogan (1999), Eaton and Groopman, (1994), Wild and Turner, (2002) were suggested the carcinogenic potency of $\mathrm{AFB}_{1}$ in several species viz, rodent, nonhuman primates, fish, and birds. However, the name aflatoxins are generally obtained from the first letter in Aspergillus and three letters from the flavus (Schoental, 1967). But it is fact that basically aflatoxins are known to be produced by Aspergillus flavus (Agrios, 1978) and later on other suggested that it is also produced by some species of Aspergillus too and may be referred as aflatoxins, viz., $B_{1}, B_{2}, G_{1}$, and $G_{2}$. In addition to these, there are two more metabolic products like $\mathrm{M}_{1}$ and $\mathrm{M}_{2}$, these are significance for direct contaminates of foods, feeds, and animals (Fig.1). Further, $\mathrm{M}_{1} \& \mathrm{M}_{2}$ are originally extracted from the milk of lactating animals fed an aflatoxin preparation that is the reason $\mathrm{M}$ designation and for $\mathrm{B}$ designation because of blue fluorescence under UV light, while G refers for the yellowgreen fluorescence under UV light.

\section{Expected avenues for spreading aflatoxin diseases to the sericulture industry}

Sericulture is an agro-based rural oriented industry. The silkworm rearing and mulberry cultivation are considered as two prominent activities of sericulture industry. Historical account of this industry date backs to five thousand $\mathrm{BC}$ and it is originated in China and it is now established that domesticated silkworm Bombyx mori is evolved from its progenitor Bombyx mendarina. During mulberry cultivation, it is of common practice 
to come across with several bacterial, viral and fungal diseases. These diseases are either airborne (foliar) or soil borne (root) in nature and reported to decreases the leaf yield around $20 \%$, besides deteriorating the leaf quality (Dandin and Giridhar, 2014). Several reports are also available where insects invade the mulberry and cause mulberry diseases, pathogens and insects. Several pesticides belong to either organochlorine, organocarbomates and organo phosphorous compounds. The environmental factors viz., temperature, humidity, and rainfall play an important role in the spread of mulberry diseases. It is of common practices to notice that, because of humid and low temperature in the environment, the fungal diseases of mulberry are commonly perpetuated in temperate climatic condition (Sengupta et al., 1991), whereas, such problems are clear evidence during winter seasons of the tropical climates (Dandin and Giridhar, 2014 and Sengupta et al., 1991).

However, among the broad categories of fungal diseases of mulberry, powdery mildew is very common during rainy and winter seasons and feeding of mildew affected leaves to silkworm adversely affects on silkworm growth and development resulting in poor cocoon yield and silk quality (Nomani et al., I970 and Sullia and Padma, 1987), leaf spot is more during rainy season (Siddaramaiah et al., 1978) and leaf rust are predominant during winter season (November-February) and matured leaves are more susceptible to this disease and in the presence of rust there will be rapid premature defoliation of leaves resulting in a shortage of leaves during late age rearing (Dandin and Giridhar, 2014), etc. The above major diseases commonly controlled (or) minimized using by common conventional practices, closely watch, timely control measures and regular monitoring are essential for managing different diseases is need of the hour rather than utilizing different commercially available fungicides, namely diathium 45, bavistain, benlite (Govindaiah et al., 1989a and Govindaiah and Sharma 1994) and commercial fertilizers, chemicals as plant growth hormones. The environmental fluctuations and Aspergillus is a facultative fungus and is able to live saprophytically in the silkworm rearing environment like soil surface and rearing appliances, silkworm feces, etc (Aoki, 1971; Ayuzawa et al., 1972). The extends of diseases are minimized to a large extends in the mulberry garden because of the recommendation of the above pesticides but it is important to note that though on one side, the fungicides minimize the diseases yet the important of aflatoxin produced by the fungus is very important to be noted it down. Such a contaminated food with aflatoxin diseased leaves feeding will affect on the growth and development in mulberry silkworm and non-mulberry silkworm (Figs. 2 \& 3), cocoon yield and ultimately silk quality.

In regard to silkworm rearing because of domestication since several years/centuries, silkworm are exposed to vagaries of environmental fluctuation ( $\mathrm{RH}$, Temperature, winter \& rainy seasons), chemical fertilizers, chemical plant growth hormones, chemical insecticides, crossing with other insects/pests to mulberry and silkworm rearing environments, unhygienic conditions in rearing environments and as a result it is accepted as a carriers of aflatoxin fungal through common practices in mulberry garden and silkworm rearing environments (Fig.4). Further, aflatoxin productions on rice and oral toxicity to silkworm larvae of extracts of larvae infected with A. flavus (Tables: 1\&2) was well documented by Ohtomo et al., (1975).

Apart from, several other diseases like bacterial, viral and microsporidia (protozoan) diseases are also predominant in the mulberry garden and silkworm rearing environments. In 
addition, infestation caused by uzifly (Exorista bombycis) inflicting 10-20\% damage to the silkworm cocoon crop is noteworthy both in tropical and temperate climatic condition (Dandin and Giridhar, 2014). Several quick measures are practiced to reduce the pathogens caused by fungal disease, namely baveria basiana, red muscardin, etc (Aoki, 1971 and Aoki et al., 1972). The utilization of fungicides not only minimizes the fungal diseases but also acts as aflatoxins. Keeping the important of aflatoxin in the light of the human health and welfare as well sericulture industry, the present review article contemplates the need of careful monitoring of aflatoxins both in the silkworm rearing and mulberry gardens too.

Table.1\&2 Showing Aflatoxin productions on rice and oral toxicity to silkworm larvae of extracts of larvae infected with A. flavus. (Source from: Ohtomo et al., 1975)
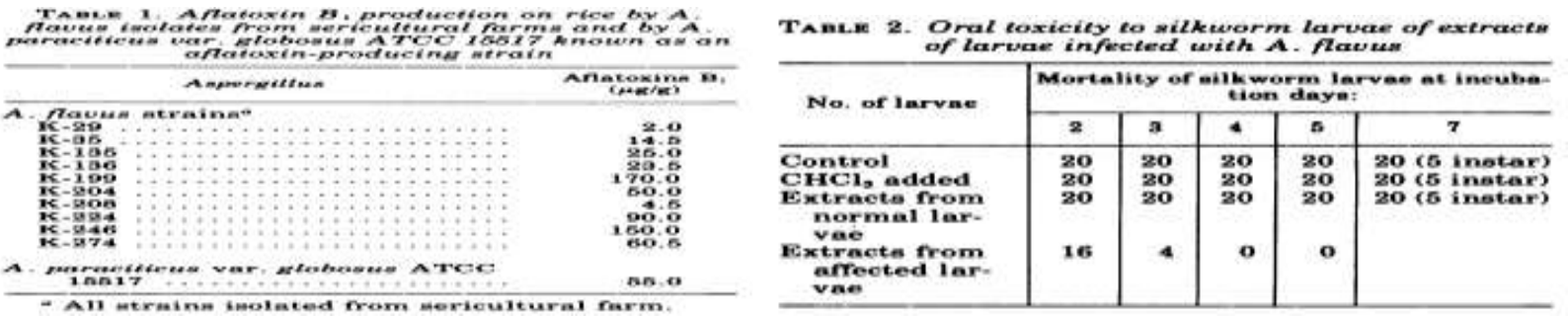

(Source from Ohtomo et al., 1975)

Fig.1 Aflatoxin and its process of distribution in different food chains and animals, etc.

(Source: Pradeep kumar et al., 2017)
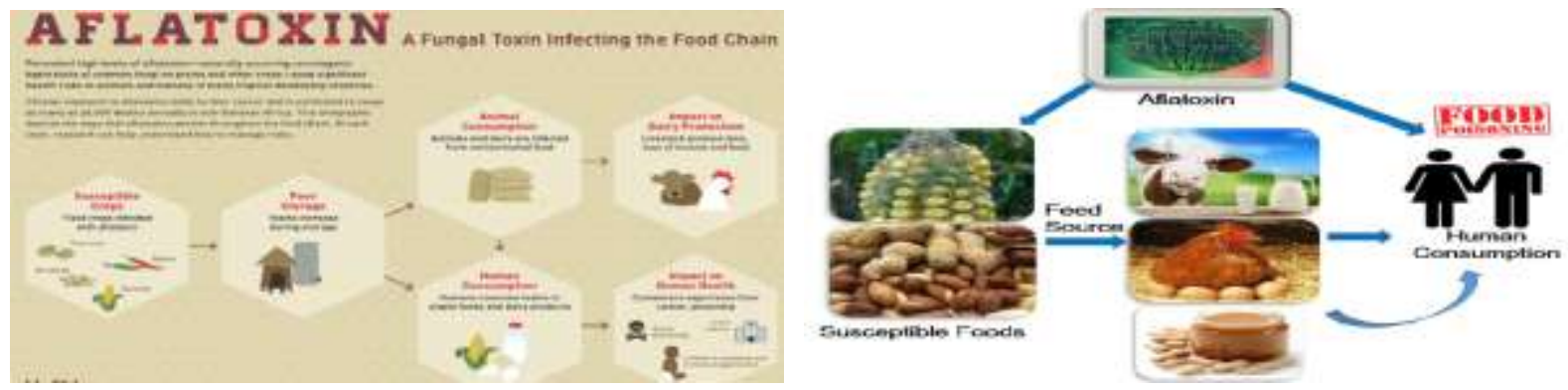

Fig.2\&3 Before and after infection by aflatoxin in mulberry silkworms and non mulberry silkworm

A

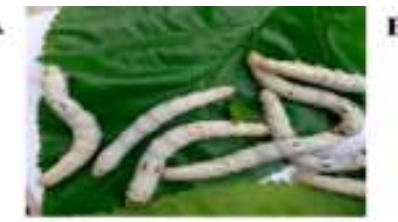

c

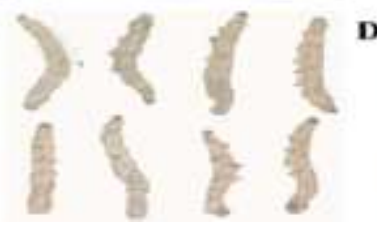

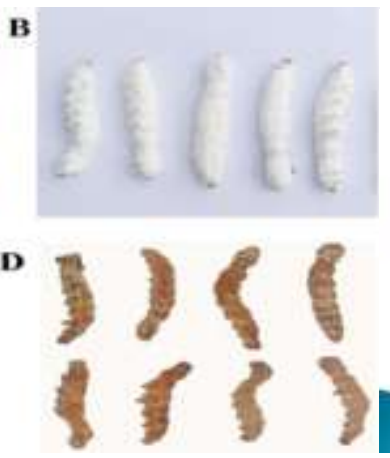

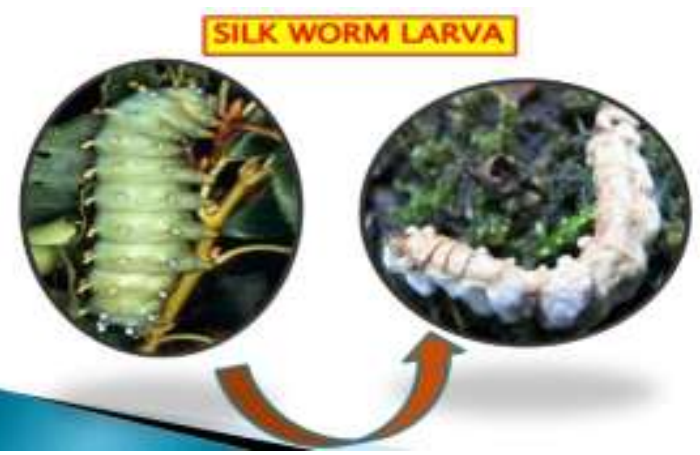


Fig.4 Come across with aflatoxin carriers (source) and infection to the silkworms Bombyx mori L.

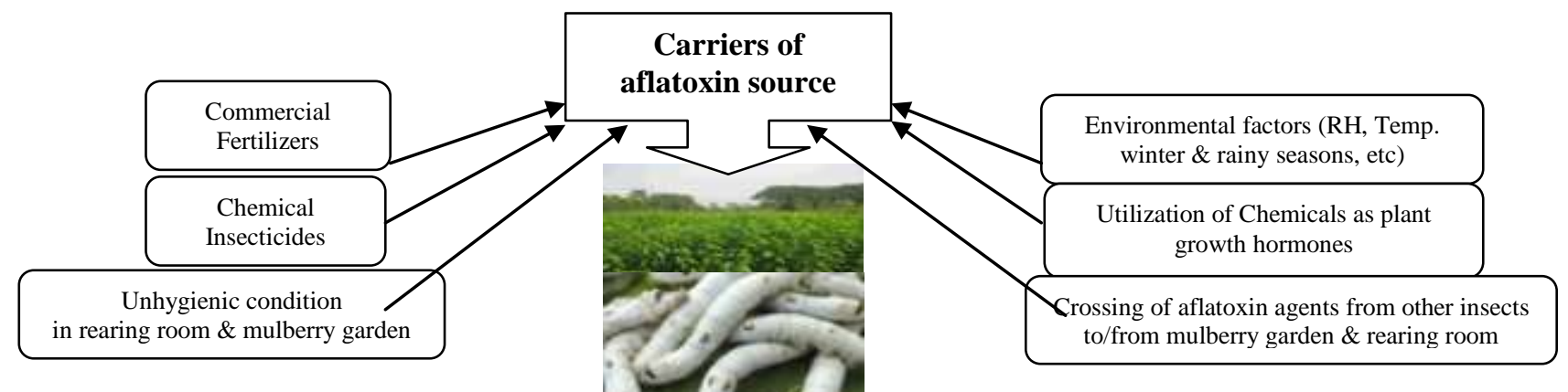

Management and controlling measures of aflatoxin production in silkworm rearing environment

First of all, as per the silkworm safety is concerned or being protected from or unlikely to cause danger diseases by aflatoxins and prevention of aflatoxin-producing fungal attack as a high alert for the sericulturists of temperate region and may overcome by maintaining optimum temp, RH \& hygienic condition in silkworm rearing climate conditions. It is suggested that minimization of chemical fertilizers \& insecticides utilization regularly in mulberry garden. Biological control of aflatoxin production in crops in the US has been approved by the Environmental Protection Agency and two commercial products based on a toxigenic A. flavus strains are being used (Afla-guardR and AF36R ) for the prevention of aflatoxin in peanuts, corn, and cottonseed (Dorner, 2009). Hence, development of silkworm breeds or races/hybrids tolerant to aspergillosis could be a worthwhile attempt by silkworm breeders. In addition, races/breeds resistant to aflatoxin are yet to be evolved in several popular silk producing countries of the world. Apart, efficient biochemical markers and genes for resistance in maize against Aspergillus could also be utilized (Chen et al., 2007).

Moreover, biotechnological methods have already be utilized for aflatoxin management
(Yu, 2012) and advanced genomic technology-based research and decoding of the A. flavus genome have supported identification of the genes responsible for production and modification of the aflatoxin biosynthesis process (Bhatnagar et al., 2003; Cleveland, 2006; Holbrook et al., 2006; Ehrlich, 2009). Further, it is suggested that aflatoxin accumulation can be reduced by utilizing transgenic $\mathrm{Bt}$ maize with insect resistance traits $(\mathrm{Wu}, 2010)$. These are the many advanced initiations to be focused for the sericulture advanced countries for control and eradication of aflatoxin-producing fungal in bivoltine producing temperate zones of the world.

In conclusion, all the studies made till now is only restricted to the Aspergillus fungal diseases with relevant to the silkworm Bombyx mori but in-depth aflatoxins relevant approaches are yet to be initiated in temperate climatic zones of the sericulture industry. As per this review work is concerned, relative humidity, temperature, rainy and winter seasons are the main weapon for quick spread of aflatoxin and the temperate zones are the sources and feasible climate for healthy growth and development of aflatoxin fungal. Hence, eradication of toxic materials aflatoxin $\left(B_{1}\right.$ and $\left.G_{1}\right)$, which are the main infection source to the silkworm in the rearing house should be thoroughly investigated. The developing new breeds/races/hybrids are yet 
to be initiated for tolerant and resistant to the aflatoxin and utilization of advanced biotechnological and nano-technological tools are badly needed to the bivoltine silk producing counties of the world. In addition, precautionary measures of feasible prevention and management strategies should be taken up especially in bivoltine producing temperate climatic zones are need of the over through numerous approaches as discussed herein.

\section{Acknowledgement}

Authors wish to express a deep sense of gratitude to the Central Silk Board and Central Sericultural Research and Training Institute, Pampore, Jammu and Kashmir for providing facilities to carrying out this review work.

\section{References}

Agrios, N. G.( 1978). Plant Pathology. Academic Press, New York, pp 703.

Aoki K (1971) Silkworm diseases in Thailand. Bull. Thai. Seric. Res. Trg. Inst. 1: 102-108.

Aoki K, Isarangkul L and Sinchaisri N (1972) On silkworm diseases, especially pebrine and Aspergillus diseases found in 1971. Bull. Thai Ser. Res. Trani. Centre, 2: 72-76.

Ayuzawa C, Sekido T, Yanakawa K, Sakura V, Kuratta W, Yaginuma $\mathrm{Y}$ and Tokora Y (1972). Agricultural Techniques manual-1.Handbook of Silkworm rearing, Fuzi publishing Co. Ltd, Tokyo, Japan.

Barry, D., Widstrom, N. W., Darrah, L. L., McMillian, W. W., Riley, T. J., Scott, G. E., and Lillehoj, E. B (1992) Maize ear damage by insects in relation to genotype and aflatoxin contamination in pre harvest maize grain. Journal of Economic Entomology 85:6, 2492 2495.
Bhatnagar, D., Ehrlich, K.C., and Cleveland, T.E. (2003) Molecular genetic analysis and regulation of aflatoxin biosynthesis. Appl. Microbiol. Biotechnol. 61, 83-93.

Blount WP. (1961) Turkey "X" disease. Turkeys. 9(2): 52, 55-58, 61, 77.

Bowen, K.L. \&Mack, T.P. (1991) Lesser cornstalk borer and aflatoxins: double trouble for peanut growers. Highlights of Agricultural Research, Alabama Agricultural Experiment Station 38: 3.

Busby WF, Wogan GN. (1984) Aflatoxins. In: Searle CD, editor. Chemical Carcinogens. Washington, DC: American Chemical Society. pp. 9451136.

Cardwell and Miller (1996) Mycotxins in food in Africa. Natural toxins, 4, 103107.

Chakrabarty AB (1981). Detoxification of aflatoxin in Corn. J. Food Prot.44: 173-176.

Chatterjee S N, Rao P R M, Jayaswal K P, Singh R, Datta R K (1993) Genetic variability in mulberry silkworm, Bombyx mori L., breeds with low silk yield. Indian J Seric 32: 69-86.

Chen, Z.Y., Brown, R.L., Damann, K.E and Cleveland, T.E. (2007) Identification of maiz kernel endosperm proteins associated with resistance to aflatoxin contamination by Aspergillus flavus. Phytopathology 97, 1094-1103.

Cleveland,T.E. (2006) "The use of crop proteomics and fungal genomics in elucidating fungus-crop interactions, "in Proceedings of the Myco-Globe Conference, Bari,32.

Dandin S B and Giridhar K. (2014) Hand book of Sericulture technologies. Central Silk Board, Bangalore.

Dandin S B and Giridhar K. (2014) Hand book of Sericulture technologies (Chapter-12, silkworm diseases, pests 
and their management). Central Silk Board, Bangalore. Pp. 393-408.

Diener UL, Cole RJ, Sanders TH, Payne GA, Lee LS, Klich MA. (1987) Epidemiology of aflatoxin formation by Aspergillus flavus. Annual Review of Phytopathology 25:249-270.

Dorner, J.W. (2009) Development of biocontrol technology to manage aflatoxin contamination in peanuts. Peanut Sci. 36, 60-67.

Eaton, D. L. and Groopman, J. D. (1994). The toxicology of aflatoxins. Academic Press, New York. Pp. 383-426.

Ehrlich, K.C. (2009) Predicted roles of uncharacterized clustered genes in aflatoxin biosynthesis. Toxins $1,37-$ 58.

Gorman, D.P and Kang, M.S. (1991) Pre harvest aflatoxin contamination in maize: resistance and genetics. Plant Breeding 107: 1-10.

Govindaiah and Sharma, D.D. (1994). Rootknot nematode, Meloidogyne incognita infesting mulberry - a review. Indian J. Seric. 33:110-113.

Govindaiah, Suryanarayana, N., Shanna, D.D and Gargi (1989a) Effect of mulching

Govindan R and Devaiah MC (1995) Aspergillosis of silkworm. Silkworm Pathology Technical Bull No.1. Dept. of Seri. UAS Bangalore, pp: 68.

Hell K., Cardwell KF., Setamou $M$ and Schulthess F. (2000) Influence of insect infestation on aflatoxin contamination of stored maize in four agroecological regions in Benin. African Entomology 8(1): 1-9.

Hesseltine CW. (1979) Introduction, definition and history of mycotoxins of importance top animal production. Interactions of mycotoxins in animal production. Natl. Acad. Sci. Washington D.C. (USA) 3-18.

Holbrook, C.C. Jr., Guo, B., Wilson, D.M and Timper, P. (2006) "The U.S. breeding program to develop peanut with drought tolerance and reduced aflatoxin contamination [abstract], In Proceedings of the International Conference on Groundnut Aflatoxin Management and Genomics, Guangzhou.

Lillehoj EB, Logoida AB, Maisch WF (1979) The fate of aflatoxin in naturally contaminated corn during the ethanol fermentation. Can. J. Microbiol. 25: 911-914.

Lubuwa, A.S.G dan J.S. Davis. (1994) Estimating the social cost of the impacts of fungi and aflatoxin in maize and peanut. p. 1.017-2.042. In E. Highly, E.J. Wright, H.J. Banks, and B.R. Champ (Eds.). Stored Product Protection. Proceeding of the $6^{\text {th }}$ Inter- national Working Conference on Stored Product Protection. Vol. 2. CAB International, UK.

Lussenhop, J.L and Wicklow, D.T. (1991) Nitidulid beetles as a source of Aspergillus flavus infective inoculum. Transactions of the Japanese Mycological Society 31: 63-74.

Lynch, R.E and Wilson, D.M. (1991) Enhanced infection of peanut, Arachis hypogaea L., seeds with Aspergillus flavus group fungi due to external scarification of peanut pods by the lesser cornstalk borer, Elasmopalpus lignosellus (Zeller). Peanut Science, 18: 110-116.

Lynch, R.E., Dicko, I.O., Some, S.A and Ouedraogo, A.P. (1991) Effect of harvest date on termite damage, yield, and aflatoxin contamination in groundnut in Burkina Faso. International Arachis Newsletter 10: 24.

Mills, J.T. (1983) Insect-fungus associations influencing seed deterioration. Phytopathology 73: 330-335. 
Moss, M. O. (1989) Mycotoxins of Aspergillus and other filamentous fungi. J. Appl. Bacteriol 67: 695-815.

Mousa W., Ghazali F M., Jinap S., Ghazali HM and Radu S (2013) Modeling growth rate and assessing aflatoxins production by Aspergillus flavus as a function of water activity and temperature on polished and brown rice. J. Food Sci. 78(1): 1-8.

Nagaraju, J and Goldsmith, M.R. (2002) Silkworm genomics-Progress and prospects. Current Science, 83, 411425.

Nomani, M.K.R., Mukherjee, P.K and Krishnaswami, S. (1970) Studies on the effect of feeding multivoltine silkworms (Bombyx mori L.) larvae with mildew affected leaves. Indian J.Seric.9:49-52.

Nomura, H (1897) Occurrence of Aspergillus disease in silkworm larvae. Bot. Mag. (Tokyo) 11: 31-37.

Ohi, H., Miyahara, J. and Yamashita, A. 1970. Analysis of various practically important characteristics in the silkworm in early breeding generations of hybrids. Variation among strains, correlation between parents and offspring as well as relation between each character. Tech. Bull. Sericult. Exp. Sta., MAFF.93:3949.

Sauer, D.B and Burroughs, R. (1980) Fungal growth, aflatoxin production, and moisture equilibration in mixtures of wet and dry corn. Phytopathology 70: 516-521.

Schoental, R. (1967). Aflatoxins. Annu Rev Pharmacol. 7: 343-356.

Sengupta K, Govindaiah and Pradeep kumar (1991) Diseases and pests of mulberry their control. Central Sericultural Research and Training Institute, Mysore.
Sharma RS, Trivedi KR., Wadodkar UR, Murthy TN and Punjarath JS (1994) Aflatoxin B1 content in deoiled cakes, cattle feeds and damaged grains during different seasons in India. J. Food Sci. Tech. 31: 3, 244-246.

Shotwell OL (1977) A flatoxin in corn. J. Am. Oil. Chem. Soc. 54: 216A- 224A.

Siddaramaiah, Krishna Prasad, K.S \& Hegde, R.K. (1978) Epidemiological studies of mulberry leaf spot caused by Cercospora moricola Cooke. Indian J.Seric. 16: 44-47.

Sinha, K.K. \& Sinha, A.K. (1991) Effect of Sitophilus oryzae infestation on Aspergillus flavus infection and aflatoxin contamination in stored wheat. Journal of Stored Products Research 27: 65-68.

Sinha, K.K and Sinha, A.K. (1992) Impact of stored grain pests on seed deterioration and aflatoxin contamination in maize. Journal of Stored Products Research 28: 211219.

Sullia, S.B and Padma, S.D. (1987) Acceptance of mildew affected mulberry leaves by silkworm (Bombyx mori L.) and its effects on cocoon characteristics. Sericologia, 27 (4): 693-696.

Talebi E, Khademi M and Rastad A (2011) An over review on effect of aflatoxin in animal husbandry. Asian j. Exp. Biol. Sci. 2(3): 2011: 754-757.

Toshichika Ohtomo, Shigeo Murakoshi, Junta Sugiyama and Hiroshi Kurata (1975) Detection of aflatoxin B1 in silkworm Larvae attacked by an Aspergillus flavus isolate from a Sericultural Farm. Applied microbiology, dec. pp. 1034-1035.

Vander Zijden ASM, Koelensmid WAAB, Bolding J, Barett $\mathrm{CB}$, Ord OW and Philip J (1962) Isolation in crystalline form of a toxin responsible for Turkey 
X disease. Nature (London). 195: Wu, F. (2010) The Global Burden of Disease 1060-1062. Caused by Food borne Aflatoxin. WHO Commissioned Report. Geneva: World Health Organization Food Borne Disease Burden Epidemiology Reference Group.

Wogan GN. (1999) A flatoxin as a human carcinogen. Hepatology. 30 (2): 573575.

$\mathrm{Yu}$, J. (2012) Current understanding on aflatoxin biosynthesis and future perspective in reducing aflatoxin contamination. Toxins 4, 1024-1057.

\section{How to cite this article:}

Shivkumar, M.A. Ravindra and Ramya, M.N. 2019. Aflotoxin: A Higher Threat of Health Hazards for the Bivoltine Silkworms in Temperate Zones- A Review. Int.J.Curr.Microbiol.App.Sci. 8(01): 3144-3153. doi: https://doi.org/10.20546/ijcmas.2019.801.336 